\title{
The effects of high-frequency ULF wave activity on the spectral characteristics of coherent HF radar returns: a case study
}

\author{
D. M. Wright ${ }^{1}$, T. K. Yeoman ${ }^{1}$, and E. E. Woodfield ${ }^{2}$ \\ ${ }^{1}$ Department of Physics and Astronomy, University of Leicester, University Road, Leicester, LE1 7RH, UK \\ ${ }^{2}$ National Center for Atmospheric Research/High Altitude Observatory, P.O. Box 3000, Boulder, Colorado, 80307-3000, USA
}

Received: 4 December 2003 - Revised: 15 January 2004 - Accepted: 19 January 2004 - Published: 8 April 2004

\begin{abstract}
It is now a common practice to employ groundbased radars in an attempt to distinguish between those regions of the Earth's upper atmosphere which are magnetically conjugate to open and closed magnetic field lines. Radar returns from ionospheric irregularities inside the polar cap and cusp regions generally exhibit large spectral widths in contrast to those which exist on closed field lines at lower latitudes. It has been suggested that the so-called Spectral Width Boundary (SWB) might act as a proxy for the openclosed field line boundary (OCFLB), which would then be an invaluable tool for investigating reconnection rates in the magnetosphere. The exact cause of the increased spectral widths observed at very high latitudes is still subject to considerable debate. Several mechanisms have been proposed. This paper compares a dusk-sector interval of coherent HF radar data with measurements made by an induction coil magnetometer located at Troms $\varnothing$, Norway $\left(66^{\circ} \mathrm{N}\right.$ geomagnetic). On this occasion, a number of equatorward excursions of the SWB in the radar backscatter are accompanied by increases in spectral power of ULF waves in the Pc1-2 frequency band as the SWB passes overhead. Thus, these observations support the possibility that high-frequency magnetospheric wave activity at least contribute to the observed spectral characteristics and that such wave activity might play a significant role in the nightside ionosphere.
\end{abstract}

Key words. Ionosphere (auroral ionosphere) - Magnetospheric physics (MHD waves and instabilities) - Radio science (ionospheric physics)

\section{Introduction}

The use of ground-based radars for making observations of the terrestrial ionosphere and the subsequent diagnosis of dynamic magnetospheric regions and processes is well founded. The Super Dual Auroral Radar Network (Super-

Correspondence to: D. M. Wright

(dmw7@ion.le.ac.uk)
DARN; Greenwald et al., 1995) of HF coherent radars is primarily designed to monitor the global ionospheric convection pattern, which traces the motion of magnetospheric field lines under the influence of solar-terrestrial coupling. Another important application of these radars involves sounding the very high latitude ionosphere in the polar cap and cusp, in order to diagnose the dynamic phenomena which are ongoing in these regions. The spectral width associated with backscatter from ionospheric irregularities is variable and often exhibits sharp boundaries, which relate to changes in the overlying geophysical regimes. In fact, it has been proposed that the boundary between high and low spectral widths, the latter usually occurring at lower latitudes, might be a good way of identifying the open-closed field line boundary (OCFLB). There seems to be a very good agreement between the OCFLB and the Spectral Width Boundary (SWB) on the dayside. However, recent studies involving spacecraft measurements of high energy particles in the magnetosphere and auroral imager observations in conjunction with ground-based measurements have indicated that these two demarcators are not always coincident. These observations are the subject of a forthcoming paper. Presented in this paper are data from the Hankasalmi, Finland radar, one of the CUTLASS (Co-operative UK Twin Located Auroral Sounding System; Milan et al., 1997) bistatic pair and a subset of SuperDARN. The observed radar spectral widths associated with a series of dusk-sector equatorward-propagating transient features are compared with dynamic spectral measurements of the Pc1-2 wave band from a newly deployed induction coil magnetometer located in Troms $\varnothing$, Norway.

The SuperDARN radars transmit a multipulse code and the received signals for each range gate are converted into an autocorrelation function (ACF). Parameters, such as the backscatter power (relating to irregularity intensity), line-ofsight velocity of the scattering irregularities and the spectral width can be extracted from the ACF after it is processed using the fitacf fitting routine (e.g. Villain et al., 1987). It is well known that the spectral width of coherent HF radar returns is sensitive to the various regions of 
the ionosphere and the dynamic processes in the coupled magnetosphere-ionosphere system (e.g. Baker et al., 1995; Lester et al., 2001; Woodfield et al., 2002). A number of mechanisms have been suggested to explain the increased spectral widths associated with radar backscatter from the cusp. These include (André et al., 2000b) micro-scale turbulence affecting the ionospheric irregularities, the existence of time-varying electric fields caused by ULF wave activity, strong flow shears in the large-scale convection pattern and inhomogeneities localised within the radar range cell, such as small-scale field-aligned currents and vortices.

Baker et al. (1995) and Moen et al. (2001) showed that HF radar echoes from the cusp commonly exhibit multiplepeaked spectra with large widths. André et al. (1999, 2000a, b) suggested that these widths might be the result of ULF wave activity in the Pc1-2 band, which are often observed at cusp latitudes (e.g. Maynard et al., 1991; Menk et al., 1992; Erlandson and Anderson, 1996; Dyrud et al., 1997). André et al. (1999, 2000a, b) modelled the effects of broad-band ESIC waves and narrow-band EMIC waves on HF radar observations. However, an error in their modelling code failed to properly account for time-dependent velocity variations associated with the wave electric field (Ponomarenko and Waters, 2003) and as a result, overestimated the effects of ion-cyclotron waves on HF radar observations. As a consequence, Ponomarenko and Waters (2003) favour small-scale spatio-temporal structures due to particle precipitation inside a radar range cell for causing the observed large spectral widths in the cusp regions. Thus, the significance of high-frequency waves to large radar spectral widths is still a matter of great debate. However, away from the cusp region, Wright et al. (2004) presented CUTLASS radar spectral widths associated with irregularities artificially generated by the EISCAT (European Incoherent Scatter) high power heating facility at Troms $\varnothing$ (Rietveld et al., 1993). They reported increases in spectral width which occurred during periods of Pc1-2 wave activity, as detected by an induction coil magnetometer at Kilpisjärvi, Finland. The increased spectral widths were observed to be correlated, both spatially and temporally, with localised regions of Pc4 waves believed to be driven by wave-particle interactions between field-line eigenmodes and unstable drifting energetic ion-populations constituting part of the ring current. Wright et al. (2004) interpreted the spectral width features as the result of highfrequency ion-cyclotron wave activity, driven by the same energetic ions, causing a broadening of the received radar spectra. They also suggested that this effect might provide a proxy for investigation of high-frequency wave activity inside the cusp.

At high latitudes, waves with frequencies in the Pc1-2 range $(0.1-5 \mathrm{~Hz})$ include both electrostatic ion cyclotron (ESIC) and electromagnetic ion cyclotron (EMIC) waves. In contrast to ground magnetometers, which measure magnetic signatures, radars detect changes in electric fields. Thus, a ground magnetometer will only detect EMIC waves and those ESIC waves that are associated with current systems (and therefore have a magnetic signature). Technically then,
Pc1-2 waves are those detected on the ground by magnetometers. ULF waves in this frequency band in the nightside magnetosphere are generally classified as Pil waves, where the "i" refers to their irregular, non-continuous wave period. PiB waves are a subset of Pils (e.g. Heacock, 1967), which are generally associated with the occurrence of substorms and pseudo-breakups (e.g. Akasofu, 1964; Troitskaya, 1961) and have been used to identify their onset. PiBs are characterised by broad-band wave activity appearing in a burst-like fashion.

This paper discusses an interval of HF radar data where features exhibiting large spectral widths are observed simultaneously with broad-band high-frequency wave activity and which appear to be related to substorm and pseudobreakup occurrence. In their standard mode of operation auto-correlation functions (ACFs) are formed every $100 \mathrm{~ms}$ and thus this could sample the electric fields associated with waves in the Pc1-2 band without a loss of temporal resolution. However, in an attempt to reduce cross-range noise the radar data are subsequently integrated to provide one measurement every 3 or $7 \mathrm{~s}$, and this reduction in temporal resolution will lead to a loss of spectral information associated with individual waves which will then act to broaden individual spectra.

\section{Instrumentation}

The ionospheric convection velocities presented in this paper were measured by the Hankasalmi radar which forms one-half of the CUTLASS bistatic HF radar (Milan et al., 1997). They have overlapping fields of view, which, in their standard operational mode, encompass the ionosphere over Northern Scandinavia and the northern polar cap region at higher latitudes. Signals returned to the radars have undergone a Bragg-like backscattering process from field-aligned electron density irregularities in the ionosphere. The CUTLASS data reproduced here have a range resolution of $45 \mathrm{~km}$ (with the first range starting at $180 \mathrm{~km}$ from the radar) and a temporal resolution of $1 \mathrm{~min}$ on each beam.

The Wave Excitation Experimental Diagnostic (WEED) is an induction coil magnetometer designed to observe highfrequency waves in the Pc1-2 band. It was recently deployed at the Troms $\emptyset$ Geophysical Observatory $\left(69.7^{\circ} \mathrm{N}, 19.4^{\circ} \mathrm{E}\right.$ geographic) and consists of two orthogonally aligned sensors monitoring magnetic field variations in northwards and eastwards directions ( $-\mathrm{dH} / \mathrm{dt}$ and $-\mathrm{dD} / \mathrm{dt}$, respectively). It samples data at $0.1 \mathrm{~s}$ resolution. It is most responsive to wave frequencies of about $1 \mathrm{~Hz}$. These measurements are also complemented by data from a fluxgate magnetometer located at Tromsø (TRO), which has a time resolution of $10 \mathrm{~s}$ and is part of the IMAGE Scandinavian magnetometer chain.

\section{Observations and discussion}

The data presented in this section were recorded on the 9 November 2002 in the interval 21:00-00:00 UT. Spectral 


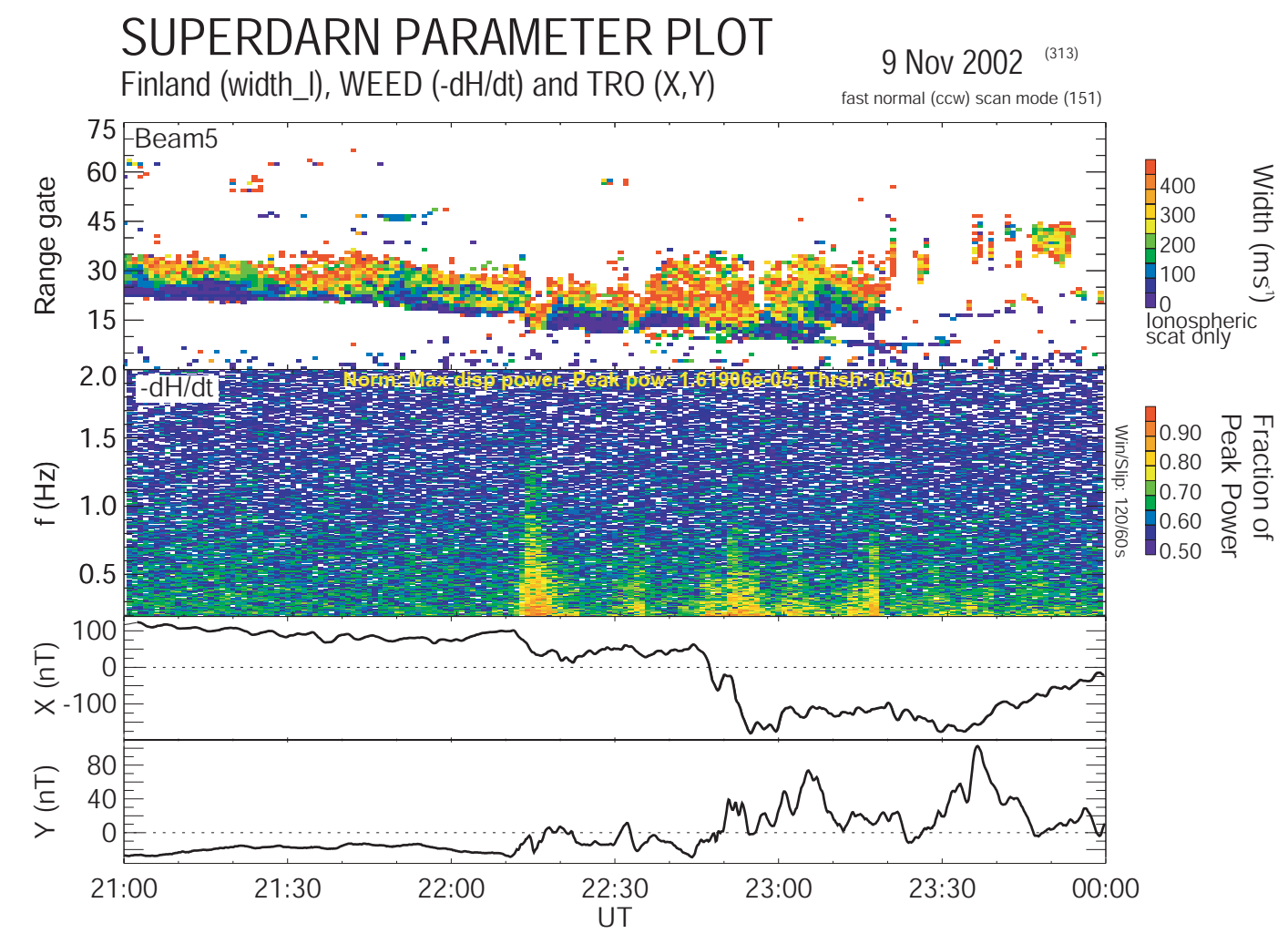

Fig. 1. Top: Spectral width (width_l) data from beam 5 of the CUTLASS, Finland radar from 21:00-00:00 UT on 9 November 2002. The range resolution of the data is $15 \mathrm{~km}$ and the lag to first range (range 0 ) is $180 \mathrm{~km}$. Middle: The spectral power of $-\mathrm{dH} / \mathrm{dt}$ measured by the Wave Excitation Experimental Diagnostic (WEED) over the same interval. The sample rate of the raw data was $0.1 \mathrm{~s}$, and a window and slip of $120 \mathrm{~s}$ and $60 \mathrm{~s}$, respectively, were employed in the dynamic spectral analysis. Bottom: Simultaneous X- and Y-component data from the Troms $\varnothing$ (TRO) IMAGE magnetometer.

width data from beam 5 of the CUTLASS Hankasalmi (Finland) radar are shown in the top panel of Fig. 1. Beam 5 overlays Troms $\varnothing$ and data from the magnetometers at this location are illustrated in the lower two panels of Fig. 1. The middle panel shows the time evolution of the dynamic spectral power of the WEED observations in the frequency range $0.1-2 \mathrm{~Hz}$ (representing most of the Pc1-2 band). There are no significant features observed above $2 \mathrm{~Hz}$. The data from the TRO magnetometer are also plotted in the lower panel of this figure. In the examination of the data prior to (not shown) and including the interval shown in Fig. 1, it is clear that the radar scatter moves gradually equatorwards (towards the radar). This is likely to be related to a combination of an expanding polar cap due to a substorm growth phase and to the relative position of the auroral oval with respect to the radar location as the Earth rotates. The backscatter exhibits a sharp spectral width boundary (SWB) where the poleward scatter have widths considerably $>200 \mathrm{~m} \mathrm{~s}^{-1}$ in contrast to those at lower latitudes which are typically $<100 \mathrm{~m} \mathrm{~s}^{-1}$. If the data from 22:00-23:00 UT are examined more closely, a number of equatorward excursions of the SWB are apparent, most notably as "bursts" in the spectral width commencing at about 22:10, 22:30 and 22:40 UT. In each case a distinct and sudden enhancement of the spectral power measured by
WEED is apparent. The spectral width features move rapidly equatorwards and pass over Troms $\varnothing$, which is conjugate to range gate 17 of beam 5 in the CUTLASS data. Measurements made over the whole IMAGE magnetometer chain, of which only TRO are shown here (lower panel of Fig. 1), suggest that these events are related to substorm activity. The spectral width features at 22:10 and 22:30 UT coincide with what appears to be pseudo-breakups, and these precede a substorm onset just after 22:40 UT which seems to be responsible for the radar features at that time.

This paper aims to address what is causing the associated changes in the spectral width parameter. During the substorm process, distended field lines dipolarise, releasing their magnetic tension as they travel towards the Earth. This also leads to the motion of plasma trapped on the field line in question, resulting in plasma precipitation into the ionosphere. In addition, some of the energy released during the magnetic field dipolarisation and subsequent ringing of the field lines will occur in the form of Alfvén waves travelling along the field lines towards the Earth. Sometimes the wave activity occurs over a broad frequency range covering the Pc1-5 bands. As discussed earlier, bursty and broad-band wave energy of this type manifests itself on the ground as a PiB signature. 


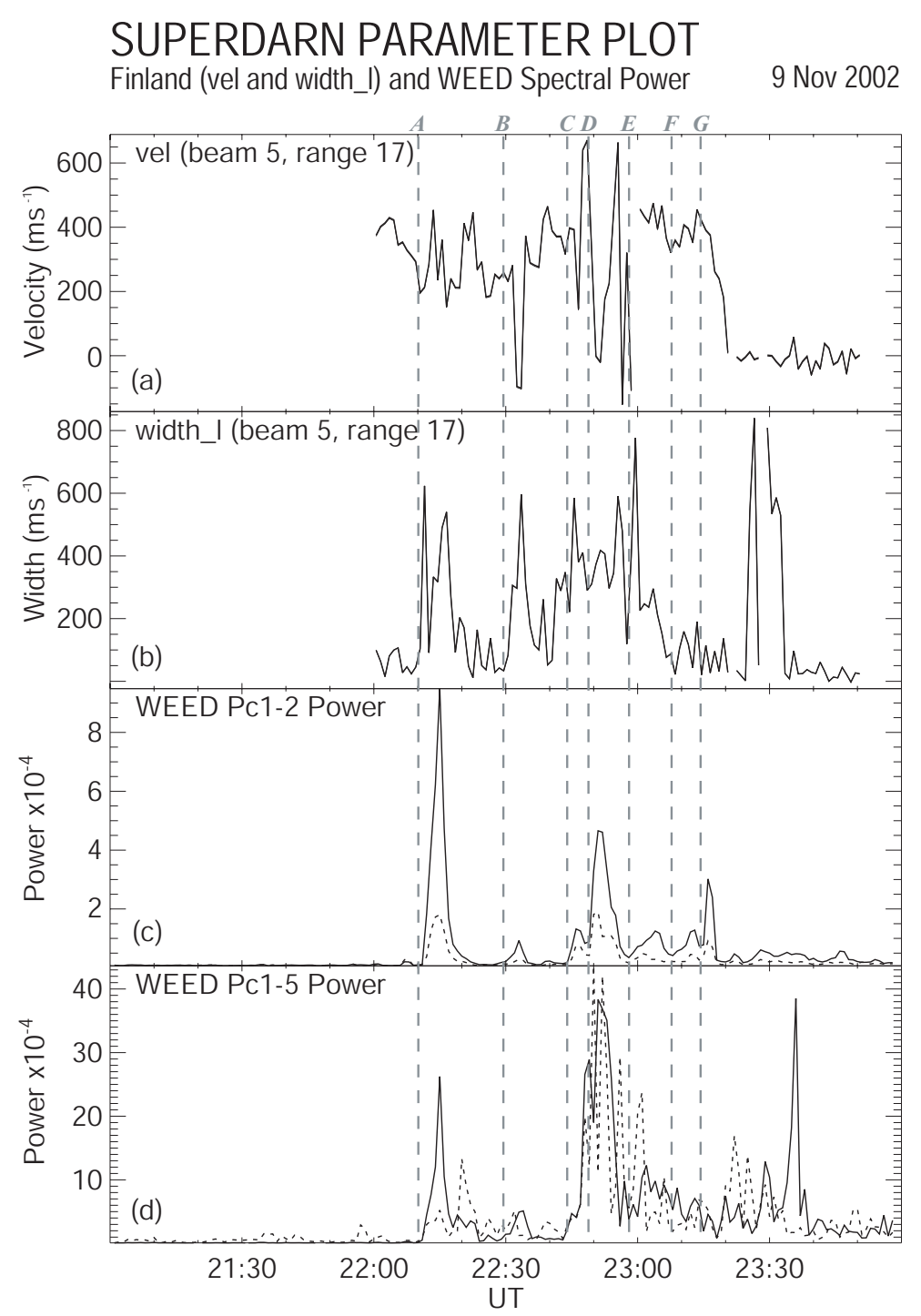

Fig. 2. Stacked time series of the line-of-sight velocity (a) and spectral width (b) from range 17 on beam 5 of the CUTLASS, Finland radar along with WEED summed spectral power in the (c) $0.1-5 \mathrm{~Hz}$ and (d) $0.002-5 \mathrm{~Hz}$ frequency bands (solid line: $-\mathrm{dD} / \mathrm{dt}$; dashed line: $-\mathrm{dH} / \mathrm{dt})$.

The modulations of WEED spectral power (middle panel, Fig. 1) indicate that there is a clear correlation between the magnetic signatures on the ground and the radar spectra as the features pass over Troms $\emptyset$. Plotted in Fig. $2 c$ is the summed $-\mathrm{dH} / \mathrm{dt}$ and $-\mathrm{dD} / \mathrm{dt}$ spectral power detected by the WEED magnetometer in the frequency range 0.1$5 \mathrm{~Hz}$ (equivalent to the combined Pc1-2 bands). Also shown (Fig. 2d) is the total spectral power across the whole equivalent Pc1-5 band $(0.002-5 \mathrm{~Hz})$. Although a perfect one-to-one relationship between the radar measurements and the broadband wave power on the ground does not exist (see Figs. 2bd), it can be seen that a number of common features can be identified. In general, the spectral power in the whole ULF wave band most closely correlates with the variation on the spectral width. However, the Pc1-2 power variations appear strongly related to the width changes. Common increases in radar spectral width and WEED Pc1-2 power are observed at around 22:10, 22:30 and 22:40 UT (marked by the vertical dashed lines labelled $A-C$ ). Comparison of the WEED spectral power variations (Figs. $2 \mathrm{c}$ and $2 \mathrm{~d}$ ) with time series of the line-of-sight velocity and spectral width at range 17 (Figs. 2a and $2 b$, respectively), clearly show that when there is an increase in high-frequency wave power (Fig. 2c), there is always a corresponding increase in the radar spectral width. This is indicated by the dashed lines marked $A-G$ on Fig. 2 . However, it should be noted that there appears to be no correlation between the magnitudes of these respective changes. The effect also appears to be distinct from the effects of the broad-band wave power, as illustrated in Fig. 2d. Throughout this interval the beam 5 line-of sight velocity detected by the radar indicates that flow was generally towards the radar, with an average flow speed of $300-400 \mathrm{~m} \mathrm{~s}^{-1}$. The radar at 


\section{SUPERDARN PARAMETER PLOT}

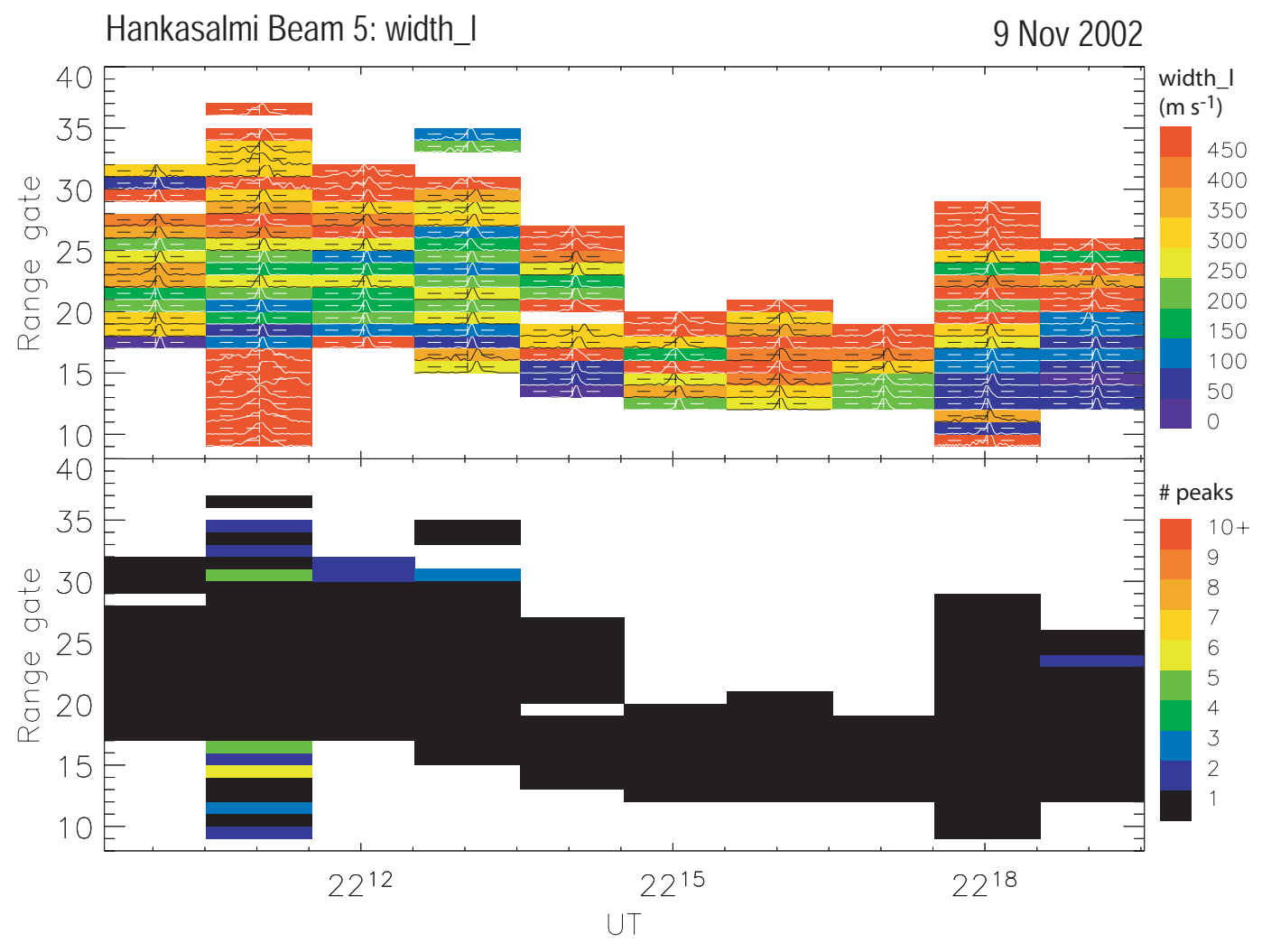

Fig. 3. Top: Spectral width (width_l) data from the CUTLASS Finland radar in the same format as Fig. 1 but for the interval 22:09:3022:19:30 UT. Overlaid on each cell are velocity power spectra derived from the FFT of the radar ACF directly. Vertical lines indicate zero Doppler velocity. Bottom: The number of spectral peaks identified, within $3 \mathrm{~dB}$ of the peak spectral power.

this time is located very close to local midnight, and these flows are consistent with antisunward irregularity flow over the pole, forming part of the global convection pattern. However, most of the increases in high-frequency wave power labelled $A-G$, including those associated with the bursty spectral width features $(A-C)$, are coincident with, or shortly followed by, sudden and short-lived reductions (and sometimes reversals) of the line-of-sight flow of up to $400 \mathrm{~m} \mathrm{~s}^{-1}$. It seems likely that this effect is related to the substorm-type processes which are ongoing in the magnetotail. However, these observations will be the subject of a future study.

The observations presented here support the view that, for this event, high-frequency wave activity could be the cause of the increases in the radar spectral width. On this day, the radar integrated its data over $3 \mathrm{~s}$ and this would then smooth out any effects due to the rapidly varying wave electric fields (see Sect. 1). The only way to properly resolve these modulations would be to examine the radar data at the pulsesequence repetition rate of $100 \mathrm{~ms}$. Such experiments are currently being undertaken.

There has been much discussion regarding the expected form of the received radar spectra. It has been suggested (Baker et al., 1995; Moen et al., 2001; André et al., 2000b) that many of the mechanisms which might lead to modifi- cation of the radar ACF would generate multi-peaked spectra. These would, in general, be the result of short-scale spatio-temporal changes occurring within a radar range cell. For example, a strong velocity shear or a vortical structure perhaps caused by a small-scale field-aligned current system would present more than one velocity component to the radar, and these would appear as multiple components in the radar spectra. In contrast to this, single component broadened spectra would be expected from electric fields exhibiting fast temporal variation due to the combination of the low spectral resolution of the radar measurements and the data integration subsequently performed by the radar in order to remove cross-range noise. ULF wave activity in the Pc1-2 band would then be expected to cause broad but single-component spectra. Highly complex spatio-temporal structures could also lead to similar broadening, if the ACF failed to resolve the multiple velocity components separately. Figure 3 addresses this issue for the data presented here. The top panel of Fig. 3 shows a section of the radar spectral width data displayed in Fig. 1. The data for the interval 22:09:30-22:19:30 UT have been selected since they cover the first equatorward excursion of the spectral width features (see Fig. 1). Overlaid on each colour-coded range cell is the appropriate power spectrum derived from the fast 
Fourier transform of the radar ACF. The lower panel of Fig. 3 is colour-coded to show the number of discernible spectral peaks from the spectra in the top panel. Only those spectral peaks which are greater than a threshold of $50 \%$ of the peak power in each spectrum are included (this level is marked by the horizontal dashed line in the spectra of the top panel). Figure 3 then clearly shows that the radar spectra during this interval do not possess multiple peaks and, in fact, exhibit only one broad spectral peak. This suggests that if highfrequency waves are dominating the received radar spectra, then the broad-band electric field modulations detected by the radar are being smoothed out by a combination of the spectral resolution of the ACF and the subsequent fitting process routinely applied to the data. In addition, the spectral widths of the features in the radar data peak at values of around $400 \mathrm{~m} \mathrm{~s}^{-1}$, which implies that the Pc1-2 waves must be modulating the velocity by up to $200 \mathrm{~m} \mathrm{~s}^{-1}$ (equivalent to electric fields of $\sim 10 \mathrm{mV} \mathrm{m}^{-1}$ ). This is consistent with spacecraft observations of the electric fields associated with conjugate ground measurements of Pc1 waves in the auroral zone (e.g. Erlandson et al., 1990; Mursula et al., 2001).

\section{Summary}

The purpose of this paper was to discuss a potential mechanism causing large spectral widths in coherent HF radar measurements. During an interval when the spectral width boundary exhibited a series of sudden equatorward moving bursts, broad-band ULF wave activity was detected on the ground at Troms $\varnothing$ using a new induction coil magnetometer called WEED. These features appear to be related to pseudobreakups and substorm onsets observed over the Scandinavian sector near local midnight. A detailed discussion of the magnetospheric processes responsible for these bursty spectral changes is the subject of a future study. However, the clear correlation between the broadening of the radar spectra and the occurrence of high-frequency wave activity provides evidence to support the suggestion that such short timescale processes may lead to increased spectral widths. This certainly appears to be the case for this interval at least. It is likely that spectral broadening is the direct result of the smoothing of the electric field modulations associated with the ULF waves as a result of integrating the backscattered signal received by the radar. The investigation of such processes offers the opportunity to gain insight into similar processes which are observed at higher latitudes. The mechanisms causing the characteristically high spectral widths recorded in the cusp is still a matter of considerable debate.

Acknowledgements. The authors would like to thank Steve Milan and Mark Lester for helpful discussions relating to this paper. We are also grateful to Lisa Baddeley and Mick Parsons for their participation in the deployment of the WEED magnetometer.

The editor in Chief thanks a referee for his help in evaluating this paper.

\section{References}

Akasofu, S.-I.: The development of auroral substorm, Planet. Space Sci., 12, 273, 1964.

André, R., Pinnock, M., and Rodger, A. S.: On the SuperDARN autocorrelation function observed in the ionospheric cusp, Geophys. Res. Lett., 26, 3353, 1999.

André, R., Pinnock, M., and Rodger, A. S.: Identification of the low-altitude cusp by Super Dual Auroral Radar Network radars: A physical explanation for the empirically derived signature, J. Geophys. Res., 105, 27 081, 2000a.

André, R., Pinnock, M., Villain, J.-P., and Hanuise, C.: On the factors conditioning the Doppler spectral width determined from SuperDARN HF radars, Int. J. Geomag. Aeron., 2, 77, 2000 b.

Baker, K. B., Dudeney, J. R., Greenwald, R. A., Pinnock, M., Newell, P. T., Rodger, A. S., Mattin, N., and Meng, C.-I.: HF radar signatures of the cusp and low-latitude boundary layer, J. Geophys. Res., 100, 7671, 1995.

Dyrud, L. P., Engebretson, M. J., Posch, J. L., Hughes, W. J., Fukunishi, H., Arnoldy, R. L., Newell, P. T., and Horne, R. B.: Ground observations and possible source regions of two types of Pc12 micropulsations at very high latitudes, J. Geophys. Res., 102, $27011,1997$.

Erlandson, R. E. and Anderson, B. J.: Pc1 waves in the ionosphere: a statistical study, J. Geophys. Res., 101, 7843, 1996.

Erlandson, R. E., Zanetti, L. J., Potemra, T. A., Block, L. P., and Holmgren, G.: Viking magnetic and electric field observations of Pc1 waves at high latitudes, J. Geophys. Res., 95, 5941, 1990.

Greenwald, R. A. , Baker, K. B., Dudeney, J. R., Pinnock, M., Jones, T. B., Thomas, E. C., Villain, J.-P., Cerisier, J.-C., Senior, C., Hanuise, C., Hunsucker, R. D., Sofko, G., Koehler, J., Nielsen, E., Pellinen, R., Walker, A. D. M., Sato, N., and Yamagishi, H.: DARN/SuperDARN: a global view of the dynamics of high-latitude convection, Space Sci. Rev., 71, 761, 1995.

Heacock, R. R.: Two subtypes of Pi micropulsations, J. Geophys. Res., 72, 3905, 1967.

Lester, M., Milan, S. E., Besser, V., and Smith, R.: A case study of $\mathrm{HF}$ radar spectra and $630.0 \mathrm{~nm}$ auroral emission in the pre midnight sector, Ann. Geophys., 19, 327, 2001.

Maynard, N. C., Aggson, T. L., Basinska, E. M., Burke, W. J., Craven, P., Peterson, W. J., Sugiura, M., and Weimer, D. R.: Magnetospheric boundary dynamics: DE1 and DE2 observations near the magnetopause and cusp, J. Geophys. Res., 96, 3505, 1991.

Menk, F. W., Fraser, B. J., Hansen, H. I., Newell, P. T., Meng, C.I., and Morris, R. J.: Identification of the magnetospheric cusp and cleft using Pc1-2 ULF pulsations, J. Atmos. Terr. Phys., 54, 1021, 1992.

Milan, S. E., Yeoman, T. K., Lester, M., Thomas, E. C., and Jones, T. B.: Initial backscatter occurrence statistics from the CUTLASS HF radars, Ann. Geophys., 15, 703, 1997.

Moen, J., Carlson, H. C., Milan, S. E., Shumilov, N., Lybekk, B., Sandholt, P. E., and Lester, M.: On the collocation between dayside auroral activity and coherent HF radar backscatter, Ann. Geophys., 9, 1531, 2001.

Mursula, K., Bräysy, T., Niskala, K., and Russell, C. T.: Pc1 pearls revisited: structured electromagnetic ion cyclotron waves on Polar satellite and on ground, J. Geophys. Res., 106, 29 543, 2001.

Ponomarenko, P. V. and Waters, C. L.: The role of Pc1-2 waves in spectral broadening of SuperDARN echoes from high latitudes, J. Geophys. Res., 30, 1122, 2003. 
Rietveld, M. T., Kohl, H., Kopka, H., and Stubbe, P.: Introduction to ionospheric heating at Troms $\varnothing-$ I. Experimental overview, J. Atmos. Terr. Phys., 55, 577, 1993.

Troitskaya, V. A.: Pulsations of the Earth's electromagnetic field with periods of 1 to 15 seconds and their connection with phenomena in the high atmosphere, J. Geophys. Res., 66, 5, 1961.

Villain J.-P., Greenwald, R. A., Baker, K. B., Ruohoniemi, J. M.: $\mathrm{HF}$ radar observations of $\mathrm{E}$ region plasma irregularities produced by oblique electron streaming, J. Geophys. Res., 92, 12327 , 1987.
Woodfield, E. E., Davies, J. A., Eglitis, P., and Lester, M.: High and variable spectral width in the pre-dawn sector: A case study involving CUTLASS, EISCAT, ESR and optical data, Ann. Geophys., 20, 501, 2002.

Wright, D. M., Yeoman, T. K., Baddeley, L. J., Davies, J. A., Dhillon, R. S., Lester, M., Milan, S. E., and Woodfield, E. E.: High resolution observations of spectral width features associated with ULF wave signatures in artificial HF radar backscatter, Ann. Geophys., 22, 169, 2004. 